\title{
Liderazgo político y el funcionario público
}

\author{
Carlos Romero-Cañadas \\ Recibido: 02/11/2014 - Aceptado: 12/12/2014
}

\begin{abstract}
Resumen
El concepto de liderazgo, hoy tan de moda, es en realidad relativamente nuevo. Previo a 1930, el interés académico en dicho concepto era poco evidenciado por la escasa disponibilidad de material en el tema. El interés era más en los aspectos de gestión operativa: ejecutar acciones específicas a través de otros en función del poder, el conocimiento de materia o rigurosos sistemas administrativos. El propósito de este artículo es una revisión del proceso evolutivo del concepto liderazgolíder: el ejecutar acciones a través de otros en función de aquellas características propias de un líder; definir dichas características; elaborar sobre cada una de ellas; y arribar a una definición concreta de líder moderno. También es nuestro propósito relacionar los conceptos de liderazgolíder con el entorno de la política, y a su vez extender estos al funcionario público como una palpable expresión del líder político, enunciando ciertos aspectos propios de estos todavía ausentes en nuestro ámbito; actitudes y conductas que generan una desconfianza institucional generalizada en la población.
\end{abstract}

\section{Palabras clave}

Liderazgo, poder, líder, política, funcionario público.

\begin{abstract}
The concept of leadership, so fashionable today, is a relatively new concept. Before 1930, there was not much academic interest in the area of leadership as evidenced by the limited availability of material on the subject. The interest was set more on the traditional aspects of operations management: executing specific actions through others on the basis of power, acquiring knowledge on the subject matter or about rigorous administrative systems. The purpose of this article is to review the evolutionary process of the concept of leadership leader: to execute actions through others based on the characteristics of a leader; to define said characteristics; to elaborate on each of them, and to arrive at a concrete definition of what constitutes a modern leader. It is also our purpose to relate the concepts of leadership leader to the political environment and to make them reach the public official as a tangible expression of the political leader stating certain aspects still absent from our environment; [knowing that] some behaviors and attitudes generate a widespread institutional mistrust among the population.
\end{abstract}

\section{Keywords}

Leadership, power, leader, politics, public official.

que se deben tomar. Los discursos están repletos de generalidades diseñadas para ganar elecciones; para mantener cierta calma en la población; para el beneficio propio. El mundo, en estos tiempos de información instantánea, ha dejado de producir líderes cuando cuentan y donde se necesitan. Ser líder político hoy día es llenar estadios, plazas y bulevares, subirse al entablado, decir

\footnotetext{
${ }^{1}$ Ingeniero Industrial, MBA en Comportamiento Organizacional, MSc en Informática MIS. Docente de Maestrías y Postgrado de la Universidad Tecnológica de El Salvador. Investigador Asociado. Experiencia en alta gerencia en empresas multinacionales.
} 
unas cuantas incoherencias y escuchar los vítores de las despistadas masas; genios regalones que invocan débiles dogmas ideológicos aprovechándose de la debilidad de las instituciones democráticas y de la pobreza de sus pueblos, para enquistarse en el poder o para aprovecharse de este. Seres inflexibles que piensan que negociar es doblegar; que buscan silenciar toda oposición; que masacran a propios y extraños, alimentando así su extrema adicción al poder en detrimento del bienestar del colectivo; y, en el peor de los casos, operan en la oscuridad, detrás del telón. El descontento con la clase política es preponderante a escala mundial. Eric Schmidt, presidente de Google, empresa americana famosa por su buscador en internet, dice:

\section{Me gustaría encontrar la manera de traer de regreso un modelo más robusto de liderazgo, responsable y respetuoso, capaz de dirigirse a los problemas y solucionarlos, en lugar de solo hablar de ellos. Nos falta la clase de liderazgo que conducirá a las sociedades hacia adelante, y algo está mal cuando es tan difícil maniobrar políticamente (Schmidt y Cohen, 2013).}

¿Cuál es la importancia de buenos líderes políticos? La prosperidad del colectivo es directamente proporcional a la calidad del liderazgo político. ¿Qué debemos esperar de nuestros líderes políticos? ¡Nada! Las sociedades no deben de esperar; las sociedades deben de exigir, demandar más; deben de forzarlos a enfrentar las consecuencias de sus actos; deben de exigir meritocracia. Un buen líder político no puede estar ciegamente amarrado a los colores de un partido o de una gremial, mucho menos a sus propios intereses sobre los intereses de aquellos que representa. Un buen líder político pondrá siempre los intereses de país por encima de todo otro interés. La incuestionable meta de todo líder político es velar por la prosperidad de todos los que representa.

¿Qué es un líder? Se usan las palabras capacidad, guiar, inspirar, comunicar, influir, entre otras, como características cruciales de un líder. Martin Luther King Jr. dice: "Un genuino líder es aquel que no busca consenso; un genuino líder es aquel que construye consenso" (King, 2014). Profundo pensamiento: el que busca consenso busca a aquellos que concuerdan con su pensamiento, el militante, el dogmático, el interesado, los allegados, la palabra negociación no está en su vocabulario, confronta el desacuerdo; en cambio, el que construye consenso construye los espacios necesarios para concertar; propone y propone; sus propósitos son para beneficio del colectivo, no es excluyente; la negociación es el concepto central de su proceder; sabe que la paciencia es una virtud.

En esencia, un líder provoca acciones del colectivo a través de la persuasión, pero para persuadir hay que tener una clara dirección. Inspira, asocia y compromete a otros con una visión; es competitivo y feliz; con un buen grado de autoconciencia y autoregulación, de empatía y socialización; comunicativo, alguien que nunca cierra las puertas al diálogo; alguien firme y contundente en su actuar cuando las circunstancias lo demandan. Añadiremos: un líder es saludable, sereno, sincero, sencillo, simpático, servicial, sinérgico, las siete S de los grandes líderes desde tiempos inmemoriales (Cubeiro y Gallardo, 2013) Es de sumo interés enfatizar en la importancia de una visión clara. Es imposible liderar sin causa. Sin causa no hay mensaje; sin mensaje no hay dirección. Las palabras clave son: inspira, asocia, compromete, visión.

Entonces, ¿cuál sería una razonable definición? Proponemos como definición de un líder moderno: Un líder inspira no doblega, mucho menos aporrea; inspira con su comportamiento, sus maneras, su compromiso; un líder asocia a aquellos en su entorno, lima asperezas entre ellos; un líder compromete a todos no solo a unos, desarrolla el esfuerzo comunitario; todo alrededor de una visión, una visión creíble que todos creamos posible, una visión común, aceptada por todos como viable, como el camino que se debe seguir. El enfoque de este artículo es una revisión del proceso evolutivo del concepto liderazgo- líder: el ejecutar acciones a través de otros en función de aquellas características propias de un líder; definir dichas características; elaborar sobre cada una de ellas; y arribar a una definición concreta y justificable de un líder moderno. También es nuestro propósito relacionar los conceptos de liderazgo-líder al entorno de la política, tanto comunitaria como nacional; y a su vez extender estos al funcionario público como una palpable expresión del líder político, enunciando ciertos aspectos propios de estos todavía ausentes en nuestro ámbito: actitudes y conductas que generan en la población una desconfianza institucional generalizada.

\section{Evolución conceptual}

El concepto de liderazgo es relativamente nuevo. Previo a 1930, el interés académico en dicho concepto era poco, evidenciado por la escasa disponibilidad de material en el tema. El interés era más en los aspectos de gestión operativa: ejecutar acciones específicas a través de otros en función del poder, del conocimiento de materia o de rigurosos sistemas administrativos. La literatura de la época se concentra primariamente en los aspectos de gestión y poder. Sin embargo, es de suma importancia examinar cómo los diferentes conceptos en el tema han venido evolucionando, dicha evolución se basa en la percepción del papel que juega el ser humano en entornos organizacionales o comunitarios ¿Qué lo motiva? Revisaremos el trabajo de varios emblemáticos autores de su época: Frederick Taylor, 
padre de la dirección científica; Max Weber, el poder emana de la autoridad (posición); Chester Barnard, la persuasión como herramienta de motivación; Mary Parker Follet, el empoderamiento, el "poder con" versus el "poder sobre", entre otros, y concluiremos con opiniones de Rosabeth Moss Kanter .

Frederick Taylor, padre de la de dirección científica, establece cuatro principios fundamentales de cómo se hace el trabajo, de cómo se administran los procesos productivos. La gerencia: elabora una ciencia para la ejecución de cada una de las operaciones del trabajo; selecciona científicamente a los trabajadores, los adiestra, les enseña y los forma; colabora cordialmente con los trabajadores para asegurarse de que el trabajo se realiza de acuerdo con los principios de la ciencia que se ha elaborado; toma bajo su responsabilidad todo aquel trabajo para el que está más capacitada que los obreros (Taylor, 1911). Según Fernanda Orozco, el llamado taylorismo provee una visión microscópica del hombre, una concepción negativa del hombre. Asume que la persona solo está motivada por las recompensas económicas, salariales y materiales. La comprobación científica se refiere al cómo y no al porqué de la acción del operario (Orozco, 2012). El taylorismo descarta la necesidad de un líder, un supervisor es suficiente.

Max Weber argumenta que el tipo de organización administrativa puramente burocrático es capaz de lograr el más alto grado de eficiencia: es el medio formal más racional que se conoce para lograr un control efectivo sobre los seres humanos, superior a cualquier otra forma de organización en cuanto a precisión, estabilidad, disciplina y operatividad. Hace posible calcular resultados precisos, necesarios para conducir la organización, y es capaz de realizar cualquier tipo de tareas administrativas. Weber considera a la burocracia como un tipo de poder y no como un sistema social; el poder emana de la autoridad, es decir, tener autoridad es tener poder. Los tipos de autoridad para Weber son: la autoridad tradicional; la autoridad carismática y la autoridad racional, legal o burocrática. Por lo tanto, Weber sugiere que el modelo de la burocracia debe estructurarse sobre la base de lo siguiente: Carácter legal de las normas y de los reglamentos, carácter formal de las comunicaciones, racionalidad en la división del trabajo, impersonalidad en las relaciones de trabajo, jerarquía bien establecida de la autoridad, rutinas y procedimientos de trabajo estandarizados en guías y manuales, competencia técnica, especialización de la administración y de los administradores, profesionalización de los participantes, completa previsibilidad del funcionamiento (Weber, 1922). En resumen, la autoridad y el poder resultante son inherentes al nivel del cargo y no a la persona. Esto descarta la necesidad de un líder, suficiente con el cargo, el poder en función de su posición.

Mary Parker Follet, en su propuesta de gestión participativa, lo que hoy conocemos como empoderamiento, sostuvo firmemente que hay principios comunes a todas las esferas de la administración: que gerentes de industria enfrentan el mismo tipo de problemas de control, poder, participación y conflicto que los administradores en el servicio público; que los motivos fundamentales involucrados en las relaciones humanas, particularmente de las reacciones de un individuo dentro de su grupo de trabajo, responden a dos interrogantes: ¿qué se desea que la gente haga en el trabajo? y ¿cómo se controla y se guía científicamente la conducta humana y las relaciones sociales en el trabajo? Follett postula cuatro principios fundamentales de organización: coordinación por contacto directo, la gente responsable debe estar en contacto directo sin hacer caso de su posición en la organización, la comunicación "horizontal" es tan importante como las cadenas "verticales" de mando.

Coordinación en las etapas iniciales, la gente interesada deberá estar involucrada en las políticas y decisiones, mientras está siendo formada o tomada y no simplemente ser informada después. Coordinación como la "relación recíproca" de todos los factores en una situación. Coordinación como un proceso continuo: una decisión ejecutiva es un momento en un proceso (Parker Follet, 1926) En resumen, el trabajo que se requiere que la gente haga está basado en los requerimientos objetivos de la situación, no en el capricho personal de un gerente en particular. El líder debe estar consciente del grupo en el que trabaja y debe considerar su trabajo como algo dirigido hacia descubrir el talento y las contribuciones de los miembros individuales. El líder debe saber cómo "crear un poder de grupo en vez de expresar un poder personal", la noción de "poder con" en vez de "poder sobre", de responsabilidad compartida y liderazgo múltiple (Serzo, 1983).

Chester Barnard introduce un nuevo concepto de líder: La habilidad de un superior de influenciar el comportamiento de sus subordinados y de persuadirlos a seguir un curso de acción en particular. La teoría de la autoridad de Barnard es notable por el resumen de las condiciones para las comunicaciones de autoridad, por la explicación de la zona de indiferencia y por su distinción entre la autoridad de posición y la autoridad de liderazgo. Con respecto a las comunicaciones de autoridad, escribió:

Una persona aceptará una comunicación como autoritativa solo cuando se cumplen cuatro condiciones: entiende la comunicación; no es 
incompatible con el propósito de la organización; es compatible con sus intereses personales; $y$ es capaz, mentalmente y físicamente, de cumplir con ella. Su concepto de zona de indiferencia es el más conocido, y estipula: existe una zona de indiferencia en cada individuo dentro de la cual las órdenes son aceptadas sin cuestionamiento alguno de la autoridad. La zona de indiferencia será mayor o menor dependiendo del grado en que los incentivos exceden la carga y los sacrificios que determinan la adherencia del individuo a la organización. Se deduce que las órdenes que serán aceptadas serán muy limitadas entre quienes apenas son inducidos a contribuir al sistema. La autoridad de posición se produce cuando la gente le adjudica autoridad a las comunicaciones desde posiciones superiores, independientemente de la capacidad personal del titular de la posición. En contraste, las personas con capacidad superior tienen autoridad de liderazgo. Cuando una persona tiene ambos tipos de autoridad, el subordinado aceptara órdenes muy fuera de su zona de indiferencia (Barnard, 1938).

French y Raven sugieren que existen cinco formas de poder: coercitivo, recompensa, legítimo, referente, experto. El poder de información fue añadido como forma de poder por Raven en 1965. La influencia social es el cambio en la creencia, actitud o comportamiento de una persona (el blanco de influencia), que resulta de la acción de otra persona (un agente que influye); y el poder social es el potencial de dicha influencia.

El poder coercitivo. Este es el poder de obligar a alguien a hacer algo contra su voluntad. A menudo es física, aunque se pueden usar otras amenazas. Es el poder de los dictadores, déspotas y matones. La coacción puede resultar en daño físico, aunque su objetivo principal es el cumplimiento. Las manifestaciones de daño a menudo se utilizan para ilustrar lo que sucederá si el cumplimiento no se gana. La coerción es también el máximo poder de todos los gobiernos. A pesar de que a menudo es visto como algo negativo, se utiliza para mantener la paz.

El poder de recompensa. Es la posibilidad de dar algo deseable, por lo tanto, se les pide cosas a cambio. Las recompensas pueden utilizarse para castigar, tal como cuando estas son retenidas.

El poder legítimo. Este es el que se invierte en un papel. Los reyes, policías, administradores tienen poder legítimo. La legitimidad proviene de un poder superior, a menudo uno con poder coercitivo. El poder legítimo es la cara aceptable del poder puro y duro.
El poder referente. Es el poder sobre una persona que desea emular al líder. Es el poder del carisma, la fama, y es ejercido por todas las celebridades, así como por los líderes sociales locales. Los que tienen el poder referente también pueden utilizarlo para la coerción; el ser humano teme la exclusión social, y solo se necesita la palabra de un líder social para ser excluido del colectivo.

El poder de experto. Consiste en poseer el conocimiento que se requiere; este es la base de toda colaboración humana.

El poder informativo. Obtener y administrar información útil que induzca a las personas a pensar y actuar diferente. Si la información es aceptada como verdadera, entonces se produce un cambio socialmente independiente, y se actúa en consecuencia (French, 1959; Raven, 1965).

Según Mulder, el poder es la capacidad para influir en el comportamiento de otros con el fin de que realicen una determinada conducta; podemos considerarlo como una característica de la que todas las personas y los grupos participan en alguna medida. De este modo, todos los miembros de una organización son al mismo tiempo agentes potenciales de influencia y sus objetivos, con independencia de la posición que ocupen. Desde esta perspectiva, cualquier relación es una relación de poder y expresa el poder relativo de sus participantes. La noción de poder suele aparecer asociada a otros dos conceptos, autoridad e influencia (Mulder, 1986).

Robert Tannenbaum y Warren Schmidt (1958) establecen la posibilidad que el propio líder escoja su estilo de liderazgo a partir de la continuidad entre la orientación a la tarea y la orientación a las relaciones. El enfoque de "contingencia", que argumenta que el estilo de liderazgo debe basarse en la situación y no en preferencias personales. El modelo desarrollado, conocido como el Tannenbaum-Schmidt Continuum, identifica siete tipos de liderazgo, y propone que mediante el entendimiento de estos se pueden identificar las opciones disponibles y escoger la más apropiada para enfrentar la situación específica. Las siete opciones corren desde el líder ejerciendo una autoridad rígida hasta el equipo teniendo total libertad de acción. El líder: Dice. Toma decisiones y espera que el equipo lo siga. El equipo tiene poca participación en la toma de decisiones. Este tipo de estilo se utiliza temprano en la existencia de un equipo, antes de que se establezca confianza entre sus miembros, o con equipos inexpertos. El líder: Vende. Toma la decisión y proporciona un análisis razonado. La aceptación por parte del equipo es importante. Aunque la decisión no cambiará, el equipo puede hacer preguntas y sentir que está siendo considerado. El líder: Sugiere. Esboza la decisión, incluye 
un análisis razonado y pregunta si hay algún comentario u objeción. Aun y cuando la decisión ya está tomada, este estilo ayuda al equipo a entender el porqué, y así no sienta que la decisión es forzada sobre ellos. El líder: Consulta. Propone una decisión y luego invita a la discusión para asegurarse de que la decisión es correcta. El equipo influye en el resultado final. El líder: Une. Presenta el problema y luego pide al equipo sugerencias y opciones que se han de considerar. A través de la discusión que sigue, el equipo ayuda al líder a decidir. El líder: Delega. Esboza el problema, proporciona parámetros de decisión y permite al equipo encontrar soluciones y tomar una decisión final. El líder sigue siendo responsable por el resultado, y controla los riesgos estableciendo límites y definiendo criterios. El líder: Abdica. Pide al equipo definir el problema, desarrollar opciones y tomar una decisión. El equipo es libre de hacer lo que sea necesario para resolver el problema, teniendo en cuenta los objetivos y necesidades organizacionales.

Stodgill (1974) propone, en su teoría de rasgos y habilidades, que las personas nacen con ciertas características para ser líderes; trece rasgos: adaptable a diferentes situaciones, alerta a su entorno social, ambicioso y orientado a resultados, resoluto, cooperativo, decisivo, fiable, dominante, energético, persistente, seguro de sí mismo, alta tolerancia al estrés, asume responsabilidad; y nueve habilidades: inteligente, conceptualmente habilidoso, creativo, diplomático, buen orador, conocedor de trabajo en equipo, organizado, persuasivo, socialmente habilidoso. Kouzes y Posner (2003), siguiendo las teorías de Stodgill, desarrollaron un instrumento, el Inventario de Prácticas en Liderazgo, con el cual determinaron siete importantes características de un líder: honestidad, ver hacia adelante, competente, inspirador, inteligente, justo y tolerante. McCall y Lombardo (1983), también siguiendo las teorías de Stodgill, investigaron líderes exitosos y no exitosos e identificaron cuatro rasgos principales a los cuales podría atribuirse su éxito o fracaso: estabilidad emocional, reconocimiento de sus errores, buenas habilidades interpersonales y amplitud intelectual.

Goleman, Boyatzis, McKee (2002) extienden los conceptos de inteligencia emocional al campo del liderazgo, afirmando que la realidad del liderazgo es sencilla: Ios líderes son personas que saben manejar sus emociones; que la clave del liderazgo se asienta en las competencias de la inteligencia emocional que poseen los líderes; en el modo en que gestionan la relación consigo mismos y con los demás. El líder del equipo tiene el poder para establecer normas; de maximizar la armonía y la colaboración para asegurar que el equipo se beneficie de los mejores talentos de cada miembro. Un líder logra esto moviendo al grupo hacia un mejor tono emocional a través del uso de imágenes positivas, de optimistas interpretaciones y normas constructivas de resonancia, y utilizando estilos de liderazgos visionarios, democráticos, afiliativos, y estilos de coaching. Por ejemplo, líderes pueden modelar el comportamiento del equipo a través de sus propias acciones, reforzando positivamente a hacer algo que construye la capacidad emocional del grupo. Esto se puede lograr mediante una sesión corta, antes de las reuniones, para asegurar que personas cuyo estado de ánimo podría estar no al óptimo puedan expresar sus sentimientos. Kenwyn Smith, de la Universidad de Pensilvania, y David Berg, de la Universidad de Yale, señalan en sus investigaciones que estas emociones en un grupo son cruciales señales de que la cuestión o evento en cuestión debe ser enfrentada y no evitarse. Configuración de las reglas requiere un líder emocionalmente inteligente, con sentido común. Los mejores líderes prestan atención y actúan con el sentido de lo que está pasando en el grupo. Bajo tal liderazgo, los equipos acumulan de manera natural y en poco tiempo una tradición común, positiva, acerca de cómo operar el uno con el otro para lograr los objetivos. (Goleman et al, 2002).

Rosabeth Moss Kanter, profesora de negocios de Havard Business School, recipiente del prestigioso Ernest L. Arbuckle Professorship. Directora del Harvard University Advanced Leadership Initiative, antes editora del Harvard Business Review, y profesora de sociología en Yale University, nos dice, en ponencias y entrevistas varias:

Una visión no es solo una pintura de lo que podría ser; es un llamado a lo mejor de nosotros, un llamado a volverse algo más; líderes deben de escoger causas que no abandonarán fácilmente, permanecer comprometidos a pesar de fracaso, y comunicar sus grandes ideas una y otra vez, en todo encuentro; líderes deben de sacar a la gente de su inercia. Ellos deben de excitar a la gente sobre algo que no se ha visto antes, algo que todavía no existe; el movimiento comunitario es parte de un despertar a las utópicas creencias que existieron en el siglo diecinueve y que hoy día existen otra vez, la creencia que creando la institución social correcta, la satisfacción humana y el crecimiento de pueden lograr.

\section{Reflexión preliminar}

Hemos recorrido casi cien años de la evolución conceptual del tema líder-liderazgo; examinando los trabajos y las teorías de destacados investigadores. Hemos escogido aquellos cuyas contribuciones marcan puntos de inflexión en el tema. Claro, hay muchos que no hemos 
incluido, importantes, pero debido al volumen del material, principalmente en los últimos cincuenta años, es prácticamente imposible incluirlos a todos. Es obvio que en esto del liderazgo juegan dos actores: el líder y el liderando. El liderando como colectivo, el equipo, y también como individuo. El enfoque del análisis a través de los años es en el líder; en sus características: internas en relación con sí mismo; externas en relación con el entorno y con el liderando, sea grupo o individuo. Llama la atención la poca atención que se le pone al liderando, siendo que la evolución de este es la causante fundamental de la evolución del líder. Las características del liderando hoy día, en medio de la pos-era informática, sus niveles educativos, entre muchos otros factores, demandan un estilo de líder totalmente diferente en su comunicación y enfoque. Una definición razonable del líder contemporáneo es: "Un líder inspira y persuade a otros, a través de un mensaje claro y conciso, a actuar en beneficio de la empresa. Las características propias de sí mismo son: saludable, sereno, sincero, sencillo, simpático, servicial, sinérgico, feliz, de convicciones firmes, de visión clara, con un buen grado de autoconciencia y autoregulación. Las características hacia su entorno: interés y compromiso, construye consensos, propositivo, busca el beneficio del colectivo sobre el propio. Las características hacia el liderando: comunicativo, persuasivo, incluye, asocia y compromete, paciente, empático, firme y contundente. Todo alrededor de una visión común, viable y creíble que genera pasión y entusiasmo".

Vamos a examinar como estos conceptos, desarrollados para el mundo empresarial, pueden trasladarse al líder político.

La política, entonces, se comprende como la distribución de poder y recursos en una comunidad a través del orden jerárquico de gobernanza, el ejercicio de control e influencia sobre otros, cuyos métodos incluyen promulgar leyes, el ejercicio de la fuerza y la negociación para hacer prevaler el ideario del promotor. La política es el campo donde, por un lado, se aspira realizar los más altos anhelos: libertad, paz, seguridad; y por el otro, es el campo de los intereses creados de grupos e individuos en detrimento de otros. La política es complicada, de ideales e ideologías encontradas, de extenso entorno; demanda líderes cuyas cualidades potencialmente exceden aquellas del líder empresarial.

\section{Liderazgo político}

El liderazgo político tiene como base el llamado liderazgo transformacional, bien expresado por James MacGregor Burns (1978), cuyos principales requisitos son: inspiración del liderando, visión y pasión, altas dosis de entusiasmo y energía. La característica principal es lo que mutuamente se ofrecen líderes y seguidores; ofrece un propósito que trasciende las metas a corto plazo y se enfoca en necesidades intrínsecas del más alto orden.

\section{El líder político}

El mundo está lleno de aspirantes a líderes políticos, pero lamentablemente pocos están a la altura de los ideales de liderazgo requeridos. Las dos características que parecer ser las de mayor carestía son integridad y responsabilidad de sus actos. No es coincidencia que la palabra político tenga connotaciones negativas en el mundo entero. El líder político es de suma importancia, ya que a través de la autoridad de gobierno decide la distribución de poder y recursos, construye asocios con otros actores, e influencia las decisiones que directamente afectan a la nación. El líder político requiere un enfoque a largo plazo, sobre cualquier interés personal a corto plazo; sus decisiones deben de afectar positivamente al mayor número de personas; más que ser un político debe ser un hombre de Estado, alguien cuya integridad y disposición de defender lo correcto está por encima del ganar una elección o el interés de mantener su cargo.

Algunas de las características principales de un buen líder político, en adición a las requeridas de un buen líder empresarial, son: lealtad hacia aquellos que representa; trabajar con todos sin importar los tintes ideológicos; carácter fuerte, con buena conciencia para resistir las tentaciones del poder; buen escucha, siempre accesible al más humilde; valeroso, tener el valor de decir la verdad y no lo que el pueblo quiere oír; tomar las decisiones difíciles aun y cuando sean impopulares; no olvidar a las minorías; alguien que construye.

Más importante aún, un líder político debe de ser, sobre todo, íntegro y transparente en su actuar; humilde y accesible, líder de todos, aceptar responsabilidad. Steven Hayward, en su libro sobre grandes líderes políticos (Hayward, 2005), dice: "La grandeza de un líder político radica en su carácter. El buen carácter no cambia a través del tiempo, tiene cualidades eternas, y siempre será algo que puede ser cultivado".

\section{Función publica}

El Comité Jurídico Interamericano (2014) determina que la función pública es toda actividad temporal o permanente, remunerada u honoraria, realizada por una persona natural en nombre del Estado o al servicio del Estado, o de sus entidades, en cualquiera de sus niveles jerárquicos. El 
servicio público es una actividad técnica, directa o indirecta, que ha sido creada y controlada para asegurar - de una manera permanente, regular, continua y sin propósitos de lucro-, la satisfacción de una necesidad colectiva de interés general, sujeta a un régimen especial de derecho público.

\section{El funcionario público}

El funcionario público es un empleado público; es un trabajador que desempeña funciones en una empresa $u$ organismo del Estado; fue electo, nombrado o seleccionado. ¿Quién paga su salario? El contribuyente. Ahora bien, dadas las características culturales de cada país en el mundo, no existe un documento universal sobre los valores éticos para ser aplicado a todos los países; sin embargo, existen valores que son comunes en muchos de estos: actitud innovadora, amigable, trabajar en equipo, capacidad para el cargo, confiable, comunicativo, calidad en el trabajo, compromiso con la sociedad, espíritu de servicio, franqueza, honestidad, imparcial, lealtad a la constitución, liderazgo, mérito, mejora continua, objetividad, presentación, profesionalización, rectitud, respeto, responsabilidad, sencillez, sensibilidad, tolerancia, transparencia, uso correcto del poder otorgado (UGT, 2013).

Vamos a explorar, a continuación, tres aspectos específicos de la función pública, el funcionario: su conducta y la sana crítica; el fracaso y el cambio, y el conflicto de intereses.

\section{Su conducta y la sana crítica}

A los ojos de la democracia, el funcionario público no es un bien, es un mal necesario. Hay que conceder a los funcionarios cierto poder; porque, sin ese poder, ¿de qué servirían? Pero las apariencias externas del poder no son indispensables para la marcha de los negocios. Hieren inútilmente la vista del público. En la democracia los funcionarios mismos sienten perfectamente que no han obtenido el derecho de colocarse por encima de los demás por su poder, sino bajo condición de descender al nivel de todos por sus maneras.

Yo no podría imaginar a nadie más unido en su forma de obrar, ni más accesible a todos $y$, además, atento a las peticiones y cortés en sus respuestas, que a un funcionario público en los Estados Unidos. Me agrada ese caminar natural del gobierno de la democracia. Esa fuerza interior inherente a la función, más que en el funcionario, en el hombre, más que en los signos exteriores del poder, advierto algo viril que admiro (De Tocqueville, 1831).
La cualidad más grande de una democracia es el libre acceso al funcionario público y, por ende, a las instituciones, característica fundamental de un buen gobierno. Sin embargo, pareciera que, media vez llegan al poder, las reglas cambian y las normas son: las apariencias externas de poder, la prebenda personal, la conveniencia propia $y$, más grave todavía, la falta de cortesía básica, aun desdén, con aquellos que los eligieron, olvidándose de que son estos los que pagan sus prerrogativas y privilegios. El antídoto a esta enfermiza transformación es la sana y dura crítica del funcionario público. Esta es, para la democracia, como el buen aceite para un motor; es un primordial requerimiento para su buen funcionamiento. Es obligación y deber de todo ciudadano fiscalizar constantemente el rendimiento del funcionario público y de su comportamiento dentro del marco de las obligaciones de su cargo, de su conducta personal dentro de las normas aceptadas por nuestra sociedad, y exigir el respeto incondicional de nuestras instituciones. Claro, siempre y cuando esta sea sana y bien intencionada, transparente y expresada con el debido respeto. Es necesario enfatizar que cuando la crítica y la respuesta se degeneran en acusaciones de tipo personal, de cuestionable lenguaje, de calificativos y actuaciones que bordan en lo infantil, entonces, el buen aceite deja de funcionar; la democracia sufre, se escuchan chillidos y fricciones, no produce resultados, su potencia y energía se consumen en diretes y retuerces. Es también el deber y obligación de todo funcionario público el aceptar la sana crítica con humildad y madurez. La vida pública es vivir en una pecera, a la vista y escrutinio constante de otros. ¿Incomodo? Por supuesto. Pero de saber anticipado y aceptado como tal. El comportamiento de nuestros funcionarios debe de ser digno en público, moral en privado. Digno en que no puede ni debe herir el sentir de un pueblo; las muestras de opulencia dejan cicatrices difíciles de sanar, prácticas que inevitablemente llevan al resentimiento y al irrespeto de sus gobernantes, y eventualmente al desorden y a la anarquía. Dignos en sus maneras y lenguaje, en su trato del ciudadano, por convicción no por conveniencia propia. La ambición es legítimo anhelo de superación; pero ¿cuándo se convierte en ese desordenado y dañino deseo de poder? Cuando el interés propio está por encima de todos y todo; y es precisamente esa desenfrenada codicia del funcionario público la que lleva a los pueblos al fracaso; esa ambición de sus mal llamados líderes es el triunfo personal y temporal de estos, refugio de su fracaso, preámbulo de Estados fallidos.

\section{El fracaso y el cambio}

La actitud del anglosajón ante el "fracaso" ha sido siempre una paradoja digna de un análisis imparcial y serio. Análisis que inevitablemente concluye con expresiones de admiración y 
respeto. Winston Churchill definía el éxito como "ir de fracaso en fracaso y terminar siempre con el mismo entusiasmo". ¿De qué otra manera hubiera podido sir Churchill procesar exitosamente una empresa tan frustrante como la segunda guerra mundial? Thomas Edison, inventor de la lámpara incandescente, llegó a los 10000 intentos fallidos antes de lograr su meta; y con cada fracaso decía: "He descubierto una nueva forma de cómo no lograr el resultado esperado". Un CEO de gran visión, quien a su llegada a la Corporación impuso un muy bien estructurado programa al cual llamó: "Se permite fracasar". La premisa era que no existen fracasos, solo éxitos parciales que eventualmente llevan al tan anhelado triunfo. Pronto se evidenciaron los efectos laterales: incremento en la iniciativa personal, propensión a tomar riesgos, innovación en métodos y procedimientos, mejora en servicio al cliente, nuevos productos. El resultado más apreciado por los accionistas, claro está, fue el mejorado rendimiento financiero y sus consecuentes incrementos en el valor bursátil de la Corporación.

Es interesante notar que esta actitud tan positiva ante el fracaso tiene una representación en las matemáticas: el simplex método, usado en operaciones de investigación, el cual plantea que una problemática tiene una sola solución óptima, pero que para llegar a ella se necesitan varias iteraciones de soluciones interinas. En nuestro ámbito, el fracaso conlleva un estigma sumamente negativo, con un calificativo de terminación fatal; el tratar y fallar es ser un fracasado; donde se premia el efímero éxito, una nota, y no la perseverancia y la trayectoria. Esta actitud inhibe la iniciativa, la innovación, la perseverancia, el tomar riesgos; nos vuelve ansiosos de resultados al corto plazo. Nuestros líderes políticos - de toda bandera, color y dogma - fomentan esta actitud demandando resultados contra objetivos inalcanzables, cuyo inevitable desenlace es remplazar al titular; el chivo expiatorio. Asumiendo que los funcionarios públicos fueron nombrados o elegidos por sus méritos y cualificaciones, debemos de exigirles que se equivoquen, que fracasen, que se embarquen en la búsqueda de la solución óptima, que no se rindan; como los sajones, que se atrevan, que traten, que perseveren, que entiendan que la solución óptima es el resultado de tratar muchas veces. El cambio es una aventura para disfrutar, una ruta de muchas bifurcaciones, donde en cada una hay que parar, tomar aliento, tomar decisiones y seguir. Lo que menos necesitamos son funcionarios públicos inseguros, inertes, quejosos de la crítica; adictos a la planificación, alérgicos a la acción; temerosos de perder el puesto.

\section{Conflicto de intereses}

¿Qué es el conflicto de intereses? Vamos a ilustrar el concepto a través de un sonado caso en Estados Unidos: la crisis de ahorros y préstamos de la década de los ochenta y principios de los noventa, que llevó a la quiebra a 747 asociaciones financieras de ese tipo. El costo final de la crisis fue de unos 160 billones de dólares, de los cuales 125 billones fueron pagados directamente por el gobierno federal de Estados Unidos (US Senate, 1991). El escándalo, Ilamado Keating Five, fue generado por las actividades de una casa de ahorro y préstamo, Lincoln Savings and Loans, de Irvine, California. El presidente de Lincoln era Charles Keating, que finalmente cumplió cinco años de prisión por su corrupta administración. Las asociaciones de ahorro y préstamo fueron desreguladas en esa época, permitiéndoles hacer inversiones altamente riesgosas con dinero de sus depositantes. En cuatro años, los activos de Lincoln S\&L aumentaron de 1.1 billones de dólares a 5.5 billones. Keating y otros operadores aprovecharon esta situación para establecer conexiones con miembros del Congreso, suministrando fondos para las campañas electorales a través de donaciones legales. La acusación central del asunto es que Charles Keating había hecho contribuciones millonarias a varios senadores de Estados Unidos a cambio de ayuda para contrarrestar los esfuerzos de reguladores federales, quienes desistieron de sus funciones, resultando en las desastrosas consecuencias antes mencionadas.

El reporte de la Comisión de Ética del Senado de Estados unidos lee:

Un conflicto de interés ocurre cuando un individuo u organización tiene intereses múltiples, y uno o varios de los cuales podrían corromper la motivación de un acto por otro. La presencia de un conflicto de interés es independiente de la ejecución de una incorrección. Por lo tanto, un conflicto de interés puede ser descubierto y voluntariamente distendido antes de que ocurra una corrupción. Una definición bastante popular es: Un conflicto de intereses es un conjunto de circunstancias que crean un riesgo que el juicio profesional o acciones sobre un interés primario se verán indebidamente influenciadas por un interés secundario. El Interés primario se refiere a los objetivos principales de la profesión o actividad, tales como la protección de clientes, la salud de los pacientes, la integridad de la investigación, los deberes del funcionario público, entre muchos otros. El interés secundario incluye no sólo la ganancia financiera, sino también tales motivos como el deseo de adelanto profesional, el deseo de hacer favores para familiares y amigos, beneficio propio o de organizaciones afiliadas. Los intereses secundarios no son tratados como malos en sí mismos, pero son objetables cuando se cree que tienen mayor peso que los intereses primarios. El conflicto en un conflicto de 
intereses existe aun y cuando una persona no esté realmente influenciada por el interés secundario. Este existe si las circunstancias son tales que dan lugar a la razonable creencia, basados en experiencias pasadas y evidencia objetiva, que estas crean un riesgo que decisiones a tomar serán indebidamente influenciadas por estos intereses secundarios (US Senate, 1991).

Muchas legislaciones en los países en vías de desarrollo no contemplan el conflicto de interés como delito. El funcionario público se ampara en "la ley no me lo prohíbe así que puedo hacerlo", aun y cuando la ley no lo faculta. El conflicto de intereses genera la apariencia de corrupción, la cual produce en la población una desconfianza institucional y cierto desdén hacia el funcionario público, evidenciados por el persistente desprestigio de la clase política.

\section{Conclusión}

Un líder político inspira y persuade a otros, a través de un mensaje claro y conciso, a actuar en beneficio de la nación. Debe ser, sobre todo, íntegro y transparente en su actuar, humilde y accesible, y poner el interés de la nación por sobre todo interés propio. La importancia de grandes líderes políticos es innegable. Líderes mediocres, líderes simples, transicionales, no son suficientes para los destinos de la nación. Se necesita de "grandes" líderes para lograr la sostenible prosperidad de nuestro pueblo. Las políticas populistas, diseñadas para el beneficio de los políticos, para asegurar su permanencia en el poder, debilitan la economía, empobreciendo a la clase media y empobreciendo aún más a los pobres. La pobreza no puede ser combatida a expensas del crecimiento económico participativo. Nuestros líderes deben comprender lo fácil que es destruir y lo difícil que es construir. Hemos definido y descrito en gran detalle que es un líder, sus características y sus valores. Ahora, nos corresponde a nosotros, los votantes, participar, exigir y echar por la puerta grande a todos aquellos "líderes" que no cumplan con nuestras expectativas. La nación así lo demanda.

\section{Referencias}

Barnard, Chester I. The Functions of the Executive (Thirtieth Anniversary ed.). Cambridge, MA: Harvard University Press, 1968.

Burns, James MacGregor. Transforming Leadership: A New Pursuit of Happiness. New York: Atlantic Monthly Press, 2003.

Burns, James Macgregor. Running Alone: Presidential Leadership_JFK to Bush II: Why It Has Failed and How We Can Fix It. New York: Basic Books, 2006.
Comité Jurídico Interamericano. Guía para el legislador. http://www.oas.org/juridico/spanish/legmodel.htm. Recuperado por Carlos Romero, 2/12/2014.

Camic, C., Gorski, P.S., \& Trubek, D.M. Max Weber's economy and society: A critical companion. Stanford, CA: Stanford University Press. 2005.

Copley, Frank Barley. Frederick Taylor Winslow. Industrial Efficiency. .New York, London. Harper \& Brothers 1923.

Daniel Goleman, Richard Boyatzis, and Annie McKee. Primal Leadership: Realizing the Power of Emotional Intelligence - Tapping into Your Team's Emotional Intelligence. Article published 4/8/2002. Harvard Business School. Working Knowdledge, retrieved /12/1/2014. http://hbswk.hbs.edu/archive/2875.html

De Tocqueville, A. ., \& Bender, T. Democracy in America. New York: Modern Library. 1981.

French, J.R.P., Jr., \& Raven, B.H. The bases of social power. In D. Cartwright et al., Studies in social power. Ann Arbor: Institute for Social Research, 1959, pp. 150-167.

Goleman, Daniel. Primal Leadership: Realizing the Power of Emotional Intelligence, Harvard Business School Press, 2002.

Hayward, Steven. Greatness: Reagan, Churchill, and the Making of Extraordinary Leaders, New York: Crown Forum, 2005.

Hery Serzo. Artículo publicado en la revista Management Today en español.

Sección "Clásicos de la Gerencia", Gerencia participativa es una aportación de Parker Follet. Diciembre de 1983, pp 37-38.

Juan Carlos Cubeiro. http://juanenciso06.blogspot. com/ Recuperado Noviembre 24, 2014, de http// juanenciso06.blogspot.com/2012/05/las-7-s-del-lideremocional.html

Luisa Fernanda Orozco, https://prezi.com. Recuperado Noviembre 20, 2014 de https://prezi.com/zrritfzbdj_s/ teoria-cientifica-por-frederick-taylor/.

McCall, M.W. Jr. and Lombardo, M.M. (1983). Off the track: Why and how successful executives get derailed. Greenboro, NC: Centre for Creative Leadership

Mary P. Follett : Creating Democracy, Transforming Management, Tonn, Joan C., New Haven: Yale University Press, 2003.

Martin Luther King, Jr. BrainyQuote.com. Recuperado November 24, 2014, from BrainyQuote.com. www.brainyquote.com/quotes/quotes/m/ martinluth166528.html

Mulder, M., De Jong, R.D., Koppelaar, L., \& Verhage, J. (Power, situation and leaders's effectiveness: an organizational field study. Journal of Applied Psychology, 1986. 71, 566-570. 
Posner, James M. Kouzes, Barry Z. (2003). The Leadership Challenge Workbook (1st ed.). Hoboken: John Wiley \& Sons.

Raven, B.H., \& French, J.R.P., Jr. Group support, legitimate power, and social influence. Journal of Personality, 1958, 26, 400-409.

Raven, B., \& French, J. Group support, legitimate power, and social influence. Journal of Personality, 1958, 26, 400409.

Raven, B. H. Social influence and power. In I.D. Steiner \& M. Fishbein (Eds.), Readings in contemporary social psychology. New York: Holt, Rinehart, \& Winston, 1965, pp. 371-382.

Schmidt, Eric, and Jared Cohen. The New Digital Age: Reshaping the Future of People, Nations and Business. 2013.

Stogdill, R.M. (1974). Handbook of leadership: A survey of the literature, New York: Free Press

Tannenbaum, A.S. and Schmitt, W.H. (1958). "How to choose a leadership pattern". Harvard Business Review, 36, March-April, 95-101.

Stogdill, R.M. Manual de liderazgo: Un estudio de la literatura. Nueva York: Free Press. (1974)

UGT. Estableciendo la función, los valores y el perfil del servidor público. UGT. 2013.http://courseware.url. edu.gt/Facultades/Facultad\%20de\%20Ciencias\%20
Pol\%C3\%ADticas\%20y\%20Sociales/Gesti\%C3\%B3n\%20 P\%C3\%BAblica\%20Territorial/Modulo\%205/Tema4/ Tema4/estableciendo_la_funcin_los_valores_y_el_ perfil_del_servidor_publico.html. Recuperado por Carlos Romero 2/12/2014.

United States Senate Select Committee on Ethics. Preliminary inquiry into allegations regarding Senators Cranston, DeConcini, Glenn, McCain, and Riegle, and Lincoln Savings and Loan: Open session hearings before the Select Committee on Ethics, United States Senate, One Hundred First Congress, second session, November 15, 1990, through January 16, 1991. Washington D.C.: Government Printing Office, 1991.

United States Senate Select Committee on Ethics. Senate Select Committee on Ethics, Investigation of Senator Alan Cranston together with Additional Views, Report of the Senate Select Committee on Ethics, S. Rep. No. 223, 102d Cong., 1st Sess. 36 (November 20, 1991). Washington D.C.: Government Printing Office, 1991.

Weber, Max, Guenther Roth, and Claus Wittich. Economy and Society: An Outline of Interpretive Sociology. Vol. 1. Berkeley: U of California, 1978.

Wolf, William B. "The Basic Barnard: an Introduction to Chester I. Barnard and His Theories of Organization and Management". Ithaca, NY: New York State School of Industrial and Labor Relations, Cornell University. 1974 